\title{
Effect of COVID-19 on computed tomography usage and critical test results in the emergency department: an observational study
}

\author{
Minu Agarwal MD, Amar Udare MD, Michael Patlas MD, Milita Ramonas MD, Amer A. Alaref MD, \\ Radu Rozenberg MD, Donald L. Ly MD, Dmitry S. Golev MD, Ken Mascola MRT(R), \\ Christian B. van der Pol MD
}

\section{Abstract}

Background: The effect of the coronavirus disease 2019 (COVID-19) pandemic on new or unexpected radiologic findings in the emergency department (ED) is unclear. The aim of this study was to determine the effect of the COVID-19 pandemic on the number of computed tomography (CT) critical test results in the ED.

Methods: We performed a retrospective observational study of ED CT usage at 4 Ontario hospitals (1 urban academic, 1 northern academic, 1 urban community and 1 rural community) over 1 month during the COVID-19 pandemic (April 2020) and over the same month 1 year earlier (April 2019; before the pandemic). The CT findings from 1 of the 4 hospitals, Hamilton Health Sciences, were reviewed to determine the number of critical test results by body region. Total CT numbers were compared using Poisson regression and CT yields were compared using the $\chi^{2}$ test.

Results: The median number of ED CT examinations per day was markedly lower during the COVID-19 pandemic than before the pandemic (82 v. 133, $p<0.01$ ), with variation across hospitals $(p=0.001)$. On review of 1717 CT reports from Hamilton Health Sciences, fewer critical test results were demonstrated on CT pulmonary angiograms $(43 \mathrm{v} .88, p<0.001)$ and CT examinations of the head $(82$ v. 112, $p<0.03$ ) during the pandemic than before the pandemic; however, the yield of these examinations did not change. Although the absolute number of all CT examinations with critical test results decreased, the number of CT examinations without critical results decreased more, resulting in a higher yield of CT for critical test results during the pandemic (46\% [322/696] v. $37 \%$ [379/1021], $p<0.01)$.

Interpretation: Emergency department CT volumes markedly decreased during the COVID-19 pandemic, predominantly because there were fewer examinations with new or unexpected findings. This suggests that COVID-19 public information campaigns influenced the behaviours of patients presenting to the ED.

oronavirus disease 2019 (COVID-19) has had a major impact on the delivery of health care worldwide. ${ }^{1}$ To prepare for a potential surge of patients with COVID-19 and to reduce the risk of COVID-19 transmission, many medical societies recommended that nonurgent medical procedures such as colonoscopy, Papanicolaou smears and mammography for cancer screening be delayed or rescheduled. ${ }^{2-4}$ Preliminary data suggest that the volume of nonurgent procedures markedly decreased during the initial phase of the COVID-19 pandemic in North America. ${ }^{5,6}$ Many governments issued policies for the provision of care; for example, the Ontario provincial government issued Directive 2 on Mar. 19, 2020, stating that all nonessential and elective health care services be stopped or reduced to minimal levels. ${ }^{?}$
In addition to the COVID-19 pandemic's effects on the delivery of elective and nonurgent health care, there is evidence of a reduction in delivery of care for diseases requiring urgent management. Garcia and colleagues found a 38\% reduction in cardiac catheterizations for ST-elevation myocardial infarction at the beginning of the pandemic in the United States. ${ }^{8}$ They hypothesized that this may have been

\section{Competing interests: None declared.}

This article has been peer reviewed.

Correspondence to: Christian van der Pol, vanderpolc@ @hsc.ca CMAJ Open 2020. DOI:10.9778/cmajo.20200148 
due to avoidance of medical care, among other possibilities. ${ }^{8}$ In Italy, pediatric emergency department (ED) visits plummeted during the pandemic as parents reported avoiding hospitals because of fear of contracting severe acute respiratory syndrome coronavirus 2, the virus that causes COVID-19.9 Many physicians and hospitals have reported a reduction in ED visits and hospital admissions for acute illness since the onset of the COVID-19 pandemic. ${ }^{10-15}$ There are, however, few to no data comparing the effects of COVID-19 on the diagnosis of illnesses of different urgency on imaging. Furthermore, the effects of the COVID-19 pandemic on the diagnosis of many acute illnesses have not been independently assessed.

Although the COVID-19 pandemic has undoubtedly affected ED workflow, the extent of its effect on disease diagnosis and specifically on the diagnosis of illness not related to COVID-19 in the ED is unclear as is the variation among hospitals in different practice settings. It is unknown if fewer patients are being diagnosed with illnesses requiring urgent treatment and if patients with diseases requiring urgent care are delaying presentation to the ED. Many illnesses requiring urgent treatment are diagnosed on computed tomography (CT); CT test results are categorized as critical if they are new or unexpected radiologic findings that could result in mortality or substantial morbidity if appropriate diagnostic or therapeutic follow-up steps are not undertaken. ${ }^{16,17}$ The purpose of this study was to determine the effect of the COVID-19 pandemic on CT critical test results in the ED.

\section{Methods}

\section{Study design}

A retrospective observational study was performed. Data on CT examination usage were collected from 4 hospitals during a 1-month period of the COVID-19 pandemic (Apr. 1-30, 2020) and compared with data from the same month 1 year earlier (Apr. 1-30, 2019; before the pandemic). The findings of CT examinations were reviewed at 1 hospital. Computed tomography examinations were identified by searching each institution's picture archiving and communication system or dictation software or both.

\section{Setting}

Data for consecutive CT scans were collected from 4 Ontario hospitals: an urban academic hospital (Hamilton Health Sciences), a northern Ontario academic hospital (Thunder Bay Regional Health Sciences Centre), an urban community hospital (Mackenzie Health) and a rural community hospital (Orillia Soldiers' Memorial Hospital). The findings from each CT scan performed at 1 hospital, Hamilton Health Sciences, during the 2 study periods were reviewed. We chose Apr. 1, 2020, as the start date for data collection for the pandemic period because a spike in cases was observed and locally reported in Hamilton during the last week of March $2020 .{ }^{18}$

\section{Data collection and extraction}

Aggregate data on ED CT volumes from each hospital were collected by investigators at each site (M.A., A.U., A.A., R.R,
D.L., D.G., K.M., C.V.P.) and pooled on a daily basis for assessment of interhospital differences in the total number of CT examinations performed.

Following this, consecutive radiology reports from Hamilton Health Sciences were reviewed individually, including all ED CT examinations of the head, CT angiograms of the head and neck (CTA-HN), CT pulmonary angiograms (CTPA) and CT examinations of the abdomen and pelvis during the 2019 and 2020 study periods, as these constitute most of the CT examinations performed in the ED at Hamilton Health Sciences. Reports were independently reviewed by 2 investigators (M.A., A.U.) blinded to study date; a third investigator (C.V.P.) was available for questions regarding categorization. To minimize confounding effects of CT examinations of the chest for the investigation of COVID-19, a potential source of bias, non-CTPA CT examinations of the chest were excluded from the analysis (50 examinations in total). ${ }^{19}$

The number of CT examinations with critical test results was documented on a per-day basis. Critical test results included any finding that was previously unknown and required new specific management (e.g., new malignancy), any new finding explaining an acute presentation (e.g., ovarian torsion) and any pre-existing condition with an acute complication (e.g., Crohn disease with active inflammation) or interval worsening (e.g., worsening metastatic disease).

In addition, a list of site-specific common and acute conditions on CT was established a priori for each body region. ${ }^{20}$ This list was not collectively exhaustive for each body region but rather was used to assess several more common and urgent conditions. For CT examinations of the head, these included acute intracranial hemorrhage and acute cerebral infarction; for CTA-HN, these included intracranial arterial thrombosis, occlusion or high-grade stenosis (> 70\%) of the carotid or vertebral arteries, ${ }^{21}$ and dural venous sinus thrombosis; for CTPA, these included pulmonary artery emboli; and for CT examinations of the abdomen and pelvis, these included acute appendicitis, diverticulitis, bowel obstructions, ureteric calculi and acute aortic syndrome. ${ }^{22-24}$ Findings that were incidental and of doubtful clinical significance were not considered as new findings (e.g., brain atrophy and microangiopathic ischemic change typical for age on CT examinations of the head, mild carotid stenosis $[<30 \%]$ on CTA-HN, dependent subsegmental atelectasis and incidental pulmonary nodules $<6 \mathrm{~mm}$ on CTPA, and cholelithiasis, diverticulosis and small fat-containing hernias on CT examinations of the abdomen and pelvis).

To establish if patients presented later in the course of acute illness during the COVID-19 pandemic than before the pandemic, the following complications of acute conditions were documented: for patients with appendicitis or diverticulitis, the presence of a phlegmon, a well-formed abscess or pneumoperitoneum, and for patients with bowel obstruction, the presence of pneumoperitoneum.

Trends in ED CT volumes were assessed at Hamilton Health Sciences over the time period April 2015 to April 2020. In addition, the total numbers of $E D$ visits at Hamilton Health Sciences were compared between April 2019 and April 2020. 


\section{Statistical analysis}

We compared ED CT volumes during the COVID-19 pandemic and before the pandemic using a Poisson regression model including the percentage reduction at all 4 hospitals. Total CT examination volumes at Hamilton Health Sciences were compared for each body region during the COVID-19 pandemic and before the pandemic, as were the number of critical test results and prespecified pathology types using Poisson regression to estimate the ratio of the means. The yield (or proportion) of CT examinations with critical test results was compared before and during the pandemic using the $\chi^{2}$ test. Smooth curve fitting for figures of total count data was computed using local polynomial regression (locally estimated scatterplot smoothing; LOESS). Interobserver agreement was calculated using Cohen's $\kappa$ for approximately $10 \%$ of cases. A $p$ value less than 0.05 defined statistical significance. All statistical analysis was performed using $\mathrm{R}$ (version 3.6.3, R Foundation for Statistical Computing).

\section{Ethics approval}

This retrospective cohort study was approved by the Hamilton Integrated Research Ethics Board. The need to obtain informed consent was waived. Aggregate data on ED CT volume from multiple institutions were pooled without sharing of individual patient data.

\section{Results}

A total of 6474 CT examinations were identified: 1717 from Hamilton Health Sciences, 1170 from Thunder Bay Regional Health Sciences Centre, 3056 from Mackenzie Health and 531 from Orillia Soldiers' Memorial Hospital. A total of 2495 ED CT examinations were performed during the pandemic study period and 3979 studies were performed during the same month 1 year earlier.

\section{All study hospitals}

The median number of ED CT examinations per day was markedly lower during the COVID-19 pandemic than before the pandemic $(82$ v. $133, p<0.001)$ at all 4 hospitals
(Table 1, Figure 1). There was a significant difference in the percentage decrease in ED CT volumes during the pandemic versus before the pandemic between the 4 hospitals $(p=0.001)$.

\section{Hamilton Health Sciences}

At Hamilton Health Sciences, the number of ED CT examinations in the month of April trended upward from 2015 to 2019 then decreased sharply in 2020 (during the pandemic); there was a $31.8 \%$ decrease between 2019 and $2020(p<$ 0.001) (Figure 2). Volumes of CT examinations of the head, CTPA and CTA-HN were significantly lower in April 2020 than in April 2019; volumes of CT examinations of the abdomen and pelvis did not differ significantly in the 2 periods (Table 2, Figure 3). During the same period, the total number of ED visits decreased by $51.9 \%$.

The number of critical test results for ED CTPA and CT examinations of the head was significantly lower during the COVID-19 pandemic than before the pandemic (Table 3, Figure 4). However, the yield for critical test results for CTPA and CT examinations of the head did not change. There was no significant change for CTA-HN and CT examinations of the abdomen and pelvis (Table 3). The number of CT examinations producing no critical test results decreased to a greater extent than the number of CT examinations producing critical test results, resulting in a net increased yield of all types of ED CT examinations with critical test results during the pandemic $(46.2 \%$ v. $37.1 \%$, $p<0.001)$. The number of critical test results for most of the prespecified conditions was not significantly different in April 2019 and April 2020 (Table 4), with the exception of acute sinusitis, mastoiditis or orbital cellulitis, which was less common during the pandemic $(p<0.001)$. The number of critical test results indicating appendicitis and diverticulitis complicated by abscess, phlegmon or pneumoperitoneum was similar before and during the pandemic; these potential adverse outcomes of delayed presentation did not increase. No patients were observed with a perforated bowel obstruction before or during the pandemic. Substantial interobserver agreement was observed for classification of CT examinations with and without critical test results $(\kappa=0.65)$.

Table 1: Emergency department CT volumes by hospital*

\begin{tabular}{|c|c|c|c|c|}
\hline \multirow[b]{2}{*}{ Hospital } & \multicolumn{2}{|c|}{$\begin{array}{l}\text { Volume of CT examinations, no. }(95 \% \mathrm{Cl}) \text {; } \\
\text { study period }\end{array}$} & \multirow{2}{*}{$\begin{array}{c}\text { Poisson } \\
\text { reduction } \\
\text { in means, \% }\end{array}$} & \multirow[b]{2}{*}{$p$ value } \\
\hline & Before pandemic & During pandemic & & \\
\hline Hamilton Health Sciences, $n=1717$ & $1021(959-1086)$ & $696(645-750)$ & 31.8 & $<0.001$ \\
\hline Thunder Bay Regional Health Sciences Centre, $n=1170$ & $697(646-751)$ & $473(431-518)$ & 32.1 & $<0.001$ \\
\hline Mackenzie Health, $n=3056$ & 1955 (1869-2044) & $1101(1037-1168)$ & 43.7 & $<0.001$ \\
\hline Orillia Soldiers' Memorial Hospital, $n=531$ & $306(273-342)$ & $225(197-256)$ & 26.5 & $<0.001$ \\
\hline Total, $n=6474$ & $3979(3856-4105)$ & 2495 (2398-2595) & 37.3 & $<0.001$ \\
\hline
\end{tabular}




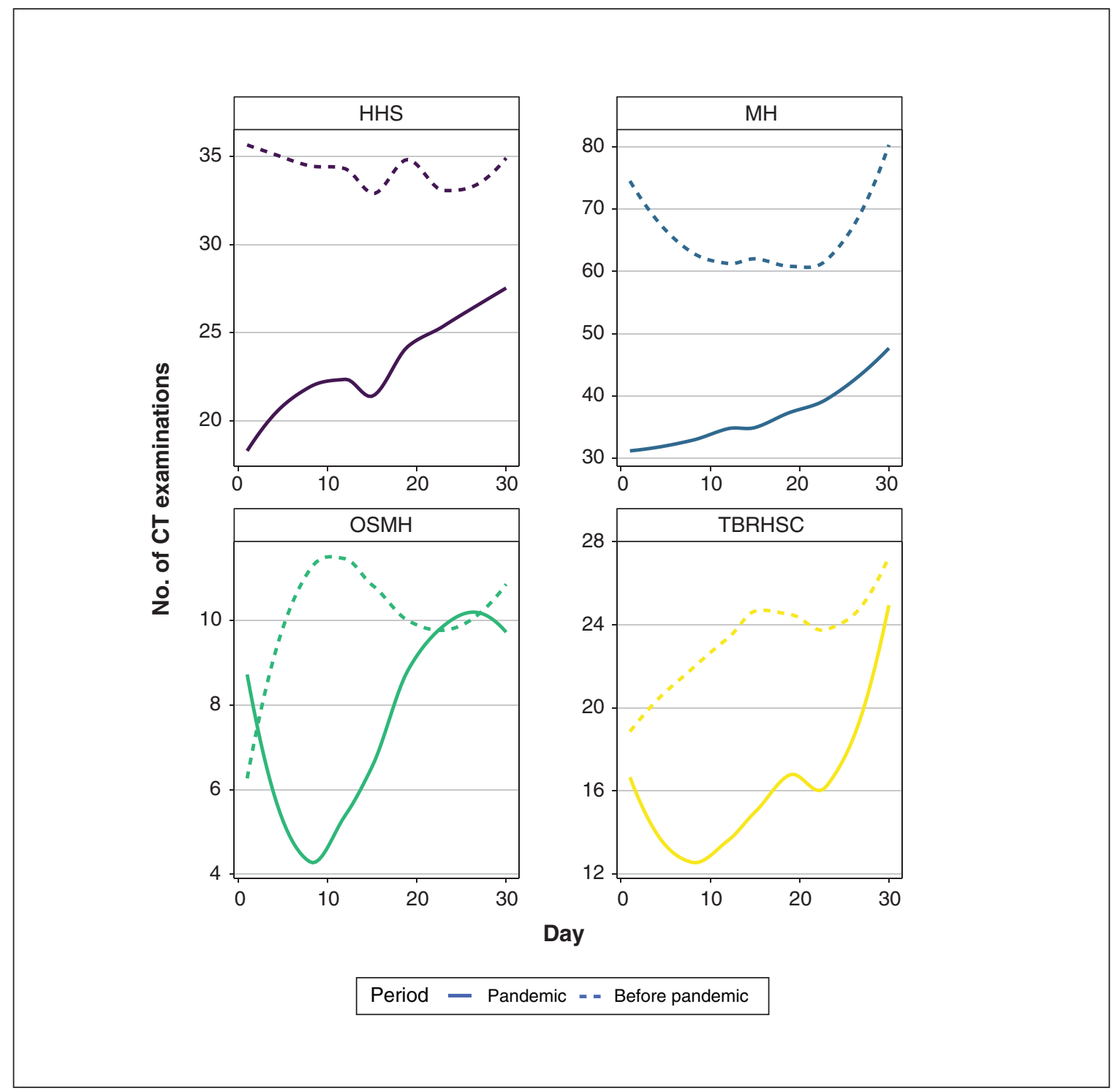

Figure 1: Emergency department CT volumes in April 2019 (before the coronavirus disease 2019 pandemic) and in April 2020 (during the pandemic). Smooth curve fitting was performed using local polynomial regression (locally estimated scatterplot smoothing; LOESS). The less smooth curves for the smaller hospitals (OSMH and TBRHSC) may be attributable to random error from smaller sample sizes. $\mathrm{CT}=$ computed tomography, $\mathrm{HHS}=$ Hamilton Health Sciences, $\mathrm{MH}=\mathrm{Mackenzie}$ Health, OSMH = Orillia Soldiers' Memorial Hospital, TBRHSC = Thunder Bay Regional Health Sciences Centre.

\section{Interpretation}

Our findings show that shortly after the COVID-19 outbreak was declared a pandemic and a province-wide emergency was announced in Ontario, critical test results on CTPA and head CT examinations were less likely, either because the associated conditions were less common or because they were less commonly diagnosed. When we compared data for April 2020 with data for the same month in 2019, we found a $37 \%$ reduction in ED CT examinations performed for body regions not typically affected by COVID-19. The magnitude of change in ED CT volumes differed significantly across the 4 hospitals, which suggests these findings vary by geographic region.
A recent study in the US showed a decline of $45 \%$ and $38 \%$ in the weekly incidence of acute myocardial infarction and stroke, respectively, during the COVID-19 pandemic. ${ }^{10}$ Similar trends have been observed with other pandemics; for example, in Ontario, $20 \%-40 \%$ reductions in ED visits were seen during the severe acute respiratory syndrome (SARS) outbreak in $2003 . .^{25-27}$

Investigators have previously raised concern regarding patients potentially avoiding the ED during pandemics because of fear of contracting infectious disease. ${ }^{11-15,26-29}$ Paradoxically, the opposite effect has been observed with other epidemics of respiratory infectious diseases including the 1993 hantavirus epidemic (in New Mexico, Arizona and Colorado) and the $2009 \mathrm{H} 1 \mathrm{~N} 1$ influenza pandemic in which ED visits 


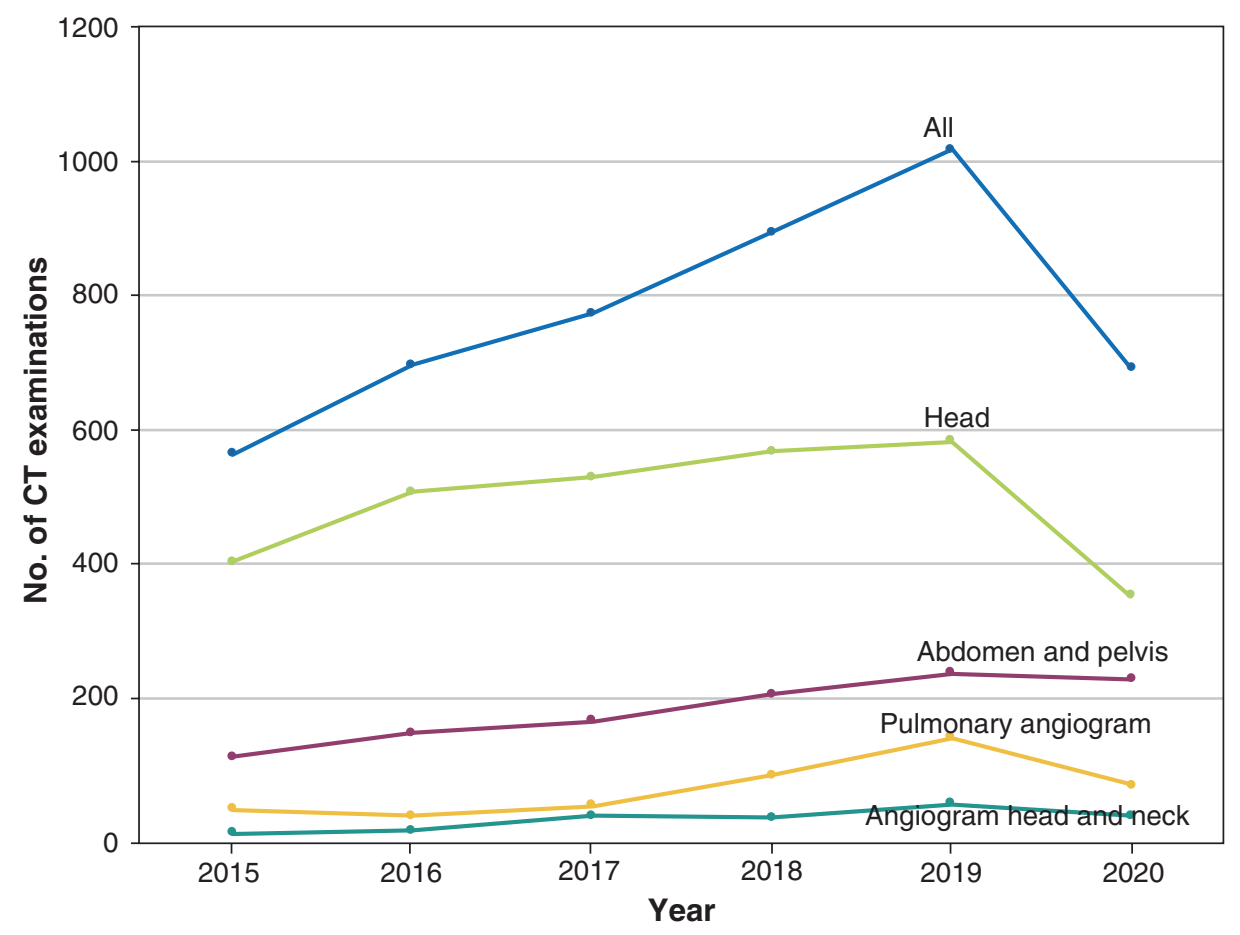

Figure 2: Trends in emergency department computed tomography (CT) examinations at Hamilton Health Sciences in the month of April from 2015 to 2020.

\begin{tabular}{|c|c|c|c|}
\hline Variable & Before pandemic & During pandemic & $p$ value \\
\hline Patient age, yr, median (range) & $67(0-103)$ & $65(0-98)$ & 0.06 \\
\hline Patient sex, $\%$ male (male to female ratio) & $45.4(464: 557)$ & $47.4(330: 366)$ & \\
\hline \multicolumn{4}{|l|}{ CT examinations, no. $(95 \% \mathrm{Cl})$} \\
\hline CT examination of the head, $n=944$ & $587(540-636)$ & $357(321-396)$ & $<0.001$ \\
\hline CT angiogram of the head and neck, $n=76$ & $47(35-63)$ & $29(19-42)$ & 0.04 \\
\hline CT pulmonary angiogram, $n=222$ & $146(123-172)$ & $76(60-95)$ & $<0.001$ \\
\hline CT examination of the abdomen and pelvis, $n=475$ & $241(212-273)$ & $234(205-266)$ & 0.7 \\
\hline Total, $n=1717$ & $1021(959-1086)$ & $696(645-750)$ & $<0.001$ \\
\hline
\end{tabular}

increased. ${ }^{30,31}$ The reason for this variation is unclear, but it seems likely that widespread dissemination of information about the contagiousness and potential severity of COVID-19 and SARS to the public may have played a role in the public's perception of these diseases. ${ }^{32}$

We found that the largest reduction in ED CT examinations occurred for patients with CT examinations without critical test results and that CT examination yield for critical test results increased during the COVID-19 pandemic. This could be due to patients with less debilitating symptoms avoiding the ED or undergoing less imaging. Further investigation of this phenomenon would be beneficial.

Prior studies had shown an upward trend of ED CT volumes over the years leading up to the COVID-19 


\begin{tabular}{|c|c|c|c|c|c|c|}
\hline \multirow[b]{2}{*}{ CT type } & \multicolumn{3}{|c|}{$\begin{array}{c}\text { CT examinations with critical test results, } \\
\text { no. }(95 \% \mathrm{Cl}) \text {; study period }\end{array}$} & \multicolumn{3}{|c|}{ Critical test result yield, \%; study period } \\
\hline & Before pandemic & During pandemic & $p$ value & Before pandemic & During pandemic & $p$ value \\
\hline CT examination of the head & $112(92-135)$ & $82(65-102)$ & 0.03 & $19.1(112 / 587)$ & $23.0(82 / 357)$ & 0.2 \\
\hline CT pulmonary angiogram & $88(71-108)$ & $43(31-58)$ & $<0.001$ & $60.3(88 / 146)$ & $56.6(43 / 76)$ & 0.7 \\
\hline $\begin{array}{l}\text { CT examination of the } \\
\text { abdomen and pelvis }\end{array}$ & $163(139-190)$ & $183(157-212)$ & 0.3 & $67.6(163 / 241)$ & $78.2(183 / 234)$ & 0.01 \\
\hline Total & 379 (342-419) & $322(288-359)$ & 0.03 & $37.1(379 / 1021)$ & $46.3(322 / 696)$ & $<0.001$ \\
\hline
\end{tabular}

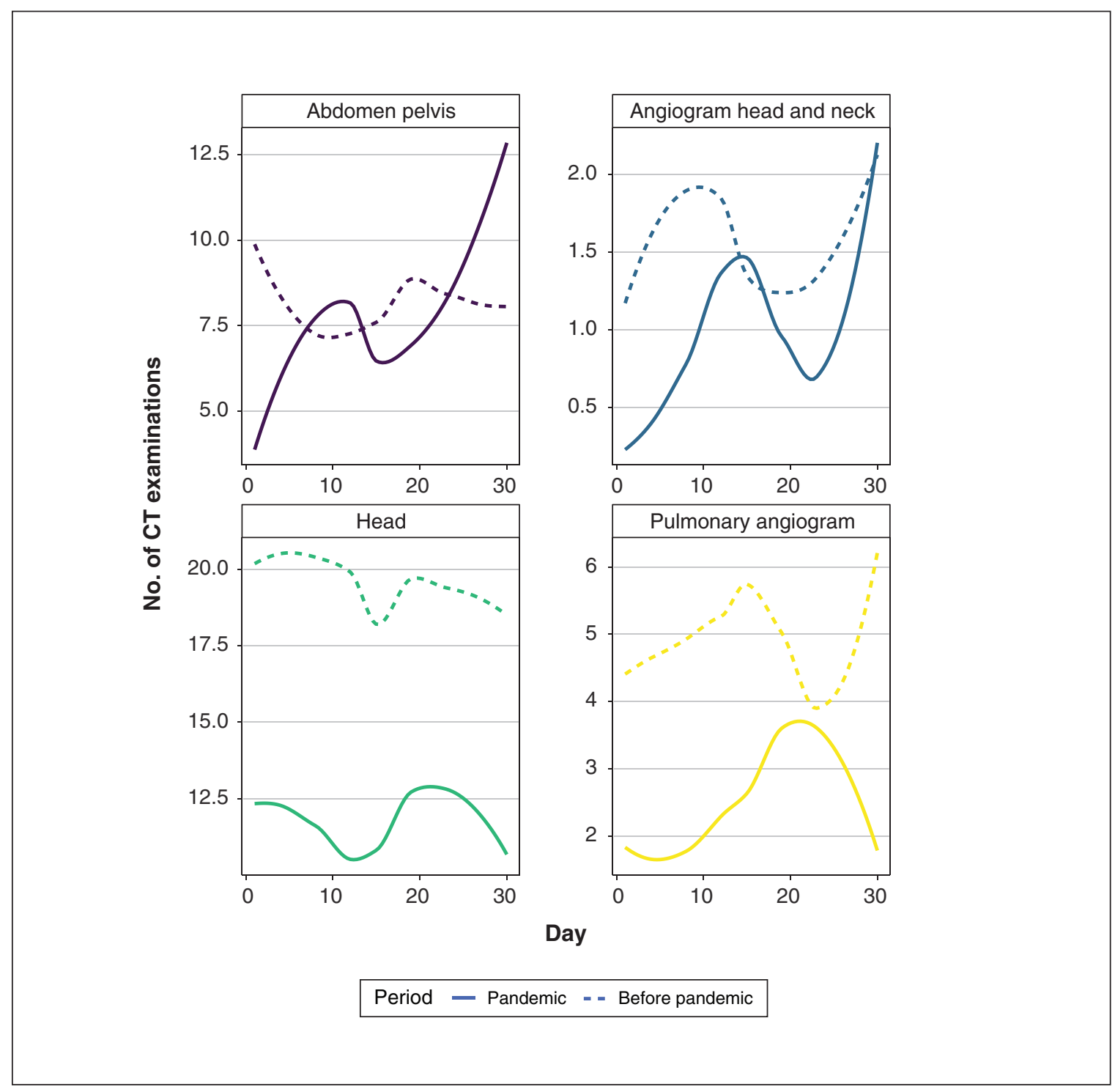

Figure 3: Emergency department computed tomography (CT) volumes by examination type at Hamilton Health Sciences. Smooth curve fitting was performed using local polynomial regression (locally estimated scatterplot smoothing; LOESS). 


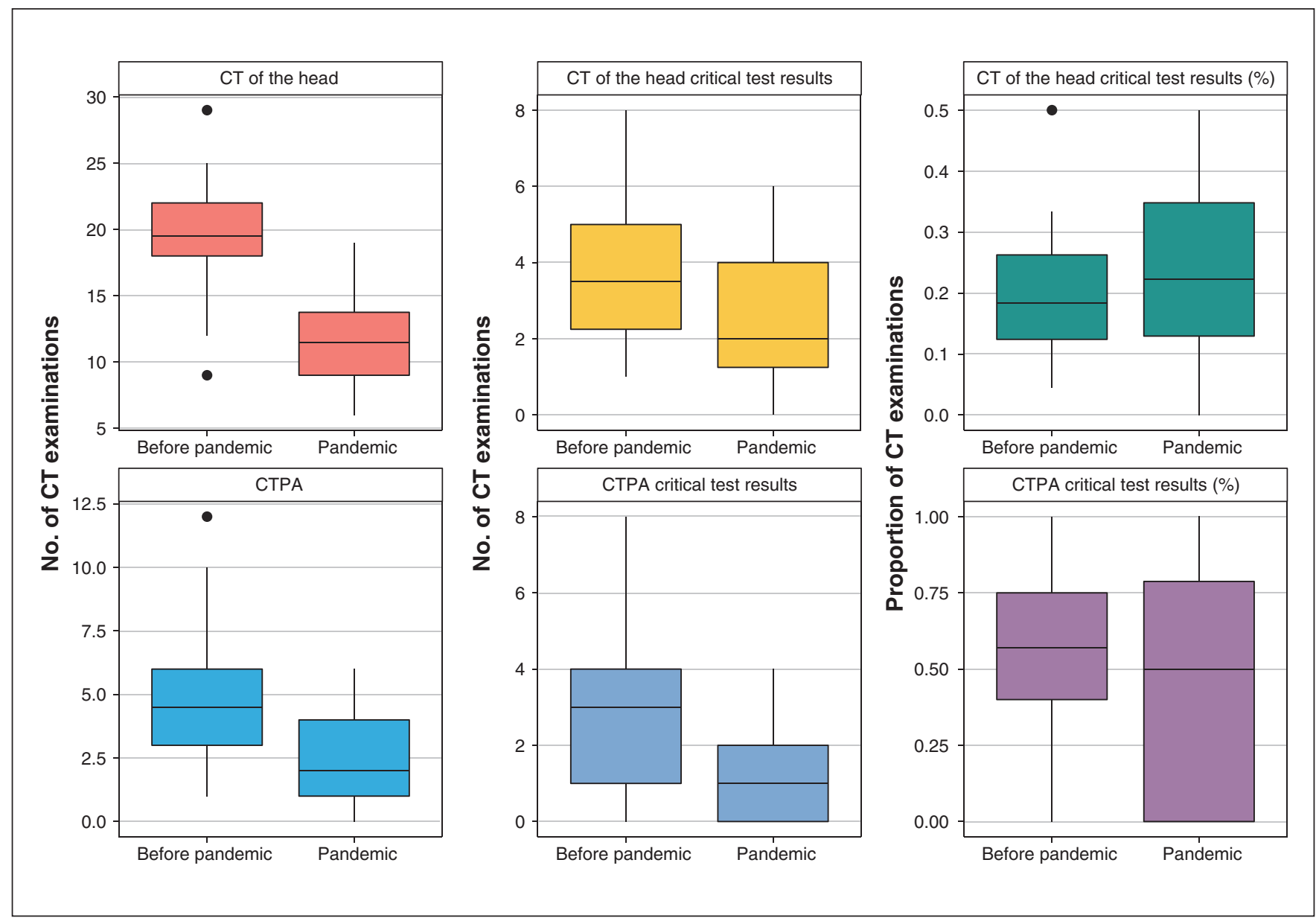

Figure 4: Comparison of the number of emergency department computed tomography (CT) examinations performed per day before and during the coronavirus disease 2019 pandemic at Hamilton Health Sciences. All of the boxplots presented in this figure demonstrate data that significantly differed during and before the pandemic. Each box indicates the IQR and contains a horizontal line indicating the median value. The whiskers indicate the minimum value (first quartile $-1.5 \times I Q R$ ) and maximum value (third quartile $+1.5 \times I Q R$ ). The points indicate outliers. CTPA = CT pulmonary angiogram, IQR = interquartile range.

pandemic that had increased disproportionately more than the growth in ED visits. ${ }^{33-36}$ It is possible that this increase had been due in part to overtesting before the pandemic. Understanding why this trend reversed during the COVID-19 pandemic, and specifically why the largest reduction occurred for patients without critical test results on CT, may help guide development of clinical decision support tools for the appropriateness of medical imaging examinations. ${ }^{37-39}$

It is unclear why volumes of CT examinations of the abdomen and pelvis slightly decreased during the pandemic; however, the number of patients with critical test results increased, resulting in a net higher yield for these examinations. Future research may help clarify this observation.

The COVID-19 pandemic has had a massive societal impact, the likes of which have not been seen since the advent of the information age. This provides investigators with a unique opportunity to improve our understanding of the influence of rapid and massive information dissemination, along with government directives, on individual behaviours. Future research exploring perceptions and the psychological effect of the COVID-19 pandemic is required. Additionally, more analysis of the effect of COVID-19 on illnesses not related to COVID-19 is desperately needed, including how our governments' and societies' response to COVID-19 has affected patients with other diseases.

\section{Limitations}

Limitations of this study include the lack of individual-level data from all 4 hospitals. A prolonged follow-up period may have provided more clarity on patient outcomes. We limited many of the outcomes assessed to 1 hospital, Hamilton Health Sciences, to optimize study expediency. We investigated a limited number of imaging examination techniques and our findings may not apply to other imaging modalities and body regions. There are many variables that could potentially lead to a reduction in ED visits during the pandemic including reduced motor vehicle transportation during the lockdown, lack of elective surgeries with subsequent postoperative complications and others that could not be controlled for in our analysis. Another limitation is that we did not analyze the pattern of $\mathrm{CT}$ examinations before and during the pandemic 
Table 4: Critical test results for emergency department CT examinations performed at Hamilton Health Sciences, by diagnosis

\begin{tabular}{|c|c|c|c|c|}
\hline \multirow[b]{2}{*}{ CT type } & \multirow[b]{2}{*}{ Critical test result } & \multicolumn{3}{|c|}{ No. of results $(95 \% \mathrm{Cl})$; study period } \\
\hline & & $\begin{array}{l}\text { Before pandemic } \\
\qquad(95 \% \mathrm{Cl})\end{array}$ & $\begin{array}{l}\text { During pandemic } \\
\qquad(95 \% \mathrm{Cl})\end{array}$ & $p$ value \\
\hline \multirow[t]{3}{*}{ CT examination of the head } & Brain infarction & $20(12-31)$ & $17(10-27)$ & 0.6 \\
\hline & Intracranial hemorrhage & $27(18-39)$ & $18(11-28)$ & 0.2 \\
\hline & $\begin{array}{l}\text { Sinusitis, mastoiditis or } \\
\text { orbital cellulitis }\end{array}$ & $22(14-33)$ & $4(1-10)$ & 0.002 \\
\hline \multirow[t]{3}{*}{$\begin{array}{l}\text { CT angiogram of the head and } \\
\text { neck }\end{array}$} & $\begin{array}{l}\text { Carotid or vertebral } \\
\text { occlusion or } \\
>70 \% \text { stenosis }\end{array}$ & $8(3-16)$ & $7(3-14)$ & 0.8 \\
\hline & $\begin{array}{l}\text { Intracranial arterial } \\
\text { thromboembolism }\end{array}$ & $1(0-6)$ & $5(2-12)$ & 0.1 \\
\hline & Dural venous sinus thrombus & $2(0-7)$ & $0(0-4)$ & 1.0 \\
\hline CT pulmonary angiogram & Pulmonary embolism & $21(13-32)$ & $12(6-21)$ & 0.1 \\
\hline \multirow{5}{*}{$\begin{array}{l}\text { CT examination of the abdomen } \\
\text { and pelvis }\end{array}$} & Appendicitis & $8^{*}(3-16)$ & $11 \dagger(5-20)$ & 0.5 \\
\hline & Diverticulitis & $24 \ddagger(15-36)$ & $22 \S(14-33)$ & 0.8 \\
\hline & Bowel obstruction & $8(3-16)$ & $13(7-22)$ & 0.3 \\
\hline & Ureteric calculi & $2(0-7)$ & $11(5-20)$ & 0.03 \\
\hline & Acute aortic syndrome & $0(0-4)$ & $0(0-4)$ & NA \\
\hline \multicolumn{5}{|c|}{$\begin{array}{l}\text { Note: } \mathrm{Cl}=\text { confidence interval, } \mathrm{CT}=\text { computed tomography, } \mathrm{NA}=\text { not applicable. } \\
\text { *Two complicated by pneumoperitoneum and } 1 \text { by abscess. } \\
\text { †Two complicated by pneumoperitoneum and } 1 \text { by pneumoperitoneum with phlegmon. } \\
\text { ‡Two complicated by abscess, } 2 \text { by phlegmon and } 2 \text { by pneumoperitoneum. } \\
\text { §Four complicated by abscess and } 1 \text { by pneumoperitoneum. }\end{array}$} \\
\hline
\end{tabular}

in relation to the pattern of ED visits and other patient data; we analyzed only ED CT critical test results. Emergency department diagnoses made without CT were not captured in our analysis. We used Apr. 1, 2020, as the start date for data collection for local reasons; data collection beginning in mid-March 2020 may have provided additional information.

\section{Conclusion}

Emergency department CT volumes substantially decreased at 4 Ontario hospitals during the COVID-19 pandemic, and although this was mostly due to fewer patients receiving CT examinations without critical test results, there were significantly fewer critical test results identified on CTPA and CT examinations of the head during the pandemic. Minimization of nonurgent health care has been an important component of the pandemic response; however, policy-makers and public health leaders must emphasize that patients with illness not typical of COVID-19 should seek medical attention.

\section{References}

1. Nicola M, Alsafi Z, Sohrabi C, et al. The socio-economic implications of the coronavirus and COVID-19 pandemic: a review. Int 7 Surg 2020;78:185-93.

2. Non-COVID-19 care framework. Atlanta: Centers for Disease Control and Prevention; updated 202015 Apr. Available: www.cdc.gov/coronavirus/2019 -ncov/hcp/framework-non-COVID-care.html (accessed 2020 June 1).

3. Cancer screening during COVID-19. Toronto: Cancer Care Ontario; updated 2020 Mar. 31. Available: www.cancercareontario.ca/en/get-checked-cancer/ screening-during-covid-19 (accessed 2020 June 1).

4. Joint GI Society message on COVID-19. Bethesda (MD): American College of Gastroenterology; 2020 Mar. 15. Available: https://gi.org/2020/03/15/joint -gi-society-message-on-covid-19/ (accessed 2020 June 1).
5. Delayed cancer screenings. Verona (WI): Epic Health Research Network; 2020 Apr. 4. Available: www.ehrn.org/delays-in-preventive-cancer-screenings-during -covid-19-pandemic/ (accessed 2020 June 1).

6. Pediatric immunizations drop in the wake of COVID-19. Verona (WI): Epic Health Research Network; 2020 Apr. 19. Available: http://ehrn.org/pediatric -immunizations-drop-in-the-wake-of-covid-19/ (accessed 2020 June 1).

7. COVID-19 Directive \#2 for health care providers (regulated health professionals or persons who operate a group practice of regulated health professionals) issued under Section 77.7 of the Health Protection and Promotion Act (HPPA), R.S.O. 1990, c. H.7. Toronto: Government of Ontario; 2020.

8. Garcia S, Albaghdadi MS, Meraj PM, et al. Reduction in ST-segment elevation cardiac catheterization laboratory activations in the United States during COVID-19 pandemic. 7 Am Coll Cardiol 2020;75:2871-2.

9. Lazzerini M, Barbi E, Apicella A, et al. Delayed access or provision of care in Italy resulting from fear of COVID-19. Lancet Child Adolesc Health 2020;4:e10-1.

10. Trends in acute MI and stroke in the ED during COVID-19. Verona (WI): Epic Health Research Network 2020 Apr. 4. Available: http://ehrn.org/ trends-in-acute-mi-and-stroke-in-the-ed-during-covid-19/ (accessed 2020 June 1)

11. Thornton J. Covid-19: A\&E visits in England fall by $25 \%$ in week after lockdown. BMF 2020;369:m1401.

12. Santana R, Sousa JS, Soares $P$, et al. The demand for hospital emergency services: trends during the first month of COVID-19 response. Port 7 Public Health 2020;38:30-6.

13. Deerberg-Wittram J, Knothe C. Do not stay at home: we are ready for you. NE7M Catalyst 2020 May 5. Available: https://catalyst.nejm.org/doi/ full/10.1056/CAT.20.0146 (accessed 2020 June 1).

14. Guo H, Zhou Y, Liu X, et al. The impact of the COVID-19 epidemic on the utilization of emergency dental services. F Dent Sci 2020 Mar 16. [Epub ahead of print]. doi: 10.1016/j.jds.2020.02.002.

15. Bres Bullrich M, Fridman S, Mandzia JL, et al. COVID-19: stroke admissions, emergency department visits, and prevention clinic referrals. Can $7 \mathrm{Neu}$ rologic Sci 2020:1-10.

16. Anthony SG, Prevedello LM, Damiano MM, et al. Impact of a 4-year quality improvement initiative to improve communication of critical imaging test results. Radiology 2011;259:802-7.

17. Lacson R, Prevedello LM, Andriole KP, et al. Four-year impact of an alert notification system on closed-loop communication of critical test results. $A 7 R$ Am 7 Roentgenol 2014;203:933-8. 
18. Mitchell D. Hamilton coronavirus cases spike as total reaches 70 , says public health. Global News 2020 Mar. 30. Available: https://globalnews.ca/ news/6749543/hamilton-coronavirus-cases-march-30/ (accessed 2020 July 22).

19. Bernheim A, Mei X, Huang M, et al. Chest CT findings in coronavirus disease-19 (COVID-19): relationship to duration of infection. Radiology 2020;295:200463.

20. Novelline RA, Rhea JT, Rao PM, et al. Helical CT in emergency radiology. Radiology 1999;213:321-39.

21. Barnett HJM, Taylor DW, Haynes RB, et al. Beneficial effect of carotid endarterectomy in symptomatic patients with high-grade carotid stenosis. $N$ Engl 7 Med 1991;325:445-53.

22. Cervellin G, Mora R, Ticinesi A, et al. Epidemiology and outcomes of acute abdominal pain in a large urban emergency department: retrospective analysis of 5340 cases. Ann Transl Med 2016:4:362.

23. Chanana L, Jegaraj MA, Kalyaniwala K, et al. Clinical profile of nontraumatic acute abdominal pain presenting to an adult emergency department. 7 Family Med Prim Care 2015;4:422-5.

24. Fagerström A, Paajanen P, Saarelainen H, et al. Non-specific abdominal pain remains as the most common reason for acute abdomen: 26-year retrospective audit in one emergency unit. Scand 7 Gastroenterol 2017;52:1072-7.

25. Order in Council 518/2020. Declaration of emergency under the Emergency Management and Civil Protection Act 2020. Toronto: Government of Ontario; updated 2020 Apr. 17. Available: www.ontario.ca/orders-in-council/oc -5182020 (accessed 2020 June 1).

26. Chen WK, Cheng YC, Chung YT, et al. The impact of the SARS outbreak on an urban emergency department in Taiwan. Med Care 2005;43:168-72.

27. Man CY, Yeung RS, Chung JY, et al. Impact of SARS on an emergency department in Hong Kong. Emerg Med (Fremantle) 2003;15:418-22.

28. Huang HH, Yen DH, Kao WF, et al. Declining emergency department visits and costs during the severe acute respiratory syndrome (SARS) outbreak. $\mathcal{F}$ Formos Med Assoc 2006;105:31-7.

29. Chang HJ, Huang N, Lee CH, et al. The impact of the SARS epidemic on the utilization of medical services: SARS and the fear of SARS. Am 7 Public Health 2004;94:562-4.

30. Brillman JC, Sklar DP, Davis KD, et al. Hantavirus: emergency department response to a disaster from an emerging pathogen. Ann Emerg Med 1994; 24:429-36.

31. Shapiro JS, Genes N, Kuperman G, et al. Health information exchange, biosurveillance efforts, and emergency department crowding during the spring 2009 H1N1 outbreak in New York City. Ann Emerg Med 2010;5 5:274-9.

32. Garfin DR, Silver RC, Holman EA. The novel coronavirus (COVID-2019) outbreak: amplification of public health consequences by media exposure. Health Psychol 2020;39:355-7.

33. Broder J, Fordham LA, Warshauer DM. Increasing utilization of computed tomography in the pediatric emergency department, 2000-2006. Emerg Radiol 2007;14:227-32.
34. Broder J, Warshauer DM. Increasing utilization of computed tomography in the adult emergency department, 2000-2005. Emerg Radiol 2006;13:25-30.

35. Larson DB, Johnson LW, Schnell BM, et al. National trends in CT use in the emergency department: 1995-2007. Radiology 2011;258:164-73.

36. Raja AS, Mortele KJ, Hanson R, et al. Abdominal imaging utilization in the emergency department: trends over two decades. Int 7 Emerg Med 2011;4:19.

37. Dunne RM, Ip IK, Abbett S, et al. Effect of evidence-based clinical decision support on the use and yield of CT pulmonary angiographic imaging in hospitalized patients. Radiology 2015;276:167-74

38. Raja AS, Ip IK, Prevedello LM, et al. Effect of computerized clinical decision support on the use and yield of CT pulmonary angiography in the emergency department. Radiology 2012;262:468-74.

39. Gupta A, Ip IK, Raja AS, et al. Effect of clinical decision support on documented guideline adherence for head CT in emergency department patients with mild traumatic brain injury. 7 Am Med Inform Assoc 2014; 21(e2):e347-51.

Affiliations: Departm=ent of Radiology (Agarwal, Udare, Patlas, Ramonas, Mascola, van der Pol), Hamilton Health Sciences; Department of Radiology (Agarwal, Udare, Patlas, Ramonas, van der Pol), McMaster University, Hamilton, Ont.; Thunder Bay Regional Health Sciences Centre (Alaref, Rozenberg); Northern Ontario School of Medicine (Alaref, Rozenberg), Thunder Bay, Ont.; Mackenzie Health (Ly), Richmond Hill, Ont.; Orillia Soldiers' Memorial Hospital (Golev), Orillia, Ont.

Contributors: Minu Agarwal, Amar Udare, Michael Patlas, Milita Ramonas and Christian van der Pol conceived of the study. Minu Agarwal, Amar Udare, Amer Alaref, Radu Rozenberg, Donald Ly, Dmitry Golev and Ken Mascola acquired the data and contributed to the analysis, which was led by Christian van der Pol. All authors were involved in drafting of the manuscript, all gave final approval of the version to be published and all agreed to be accountable for all aspects of the work.

Data sharing: All study data are available from the corresponding author. Data will be shared in accordance with institutional research ethics board protocols.

Acknowledgement: The authors acknowledge Dr. Alim Pardhan for assistance provided with data collection.

Supplemental information: For reviewer comments and the original submission of this manuscript, please see www.cmajopen.ca/content/8/3/ E568/suppl/DC1. 